\title{
Behavioral ecology of entomopathogenic nematodes
}

\author{
Edwin E. Lewis ${ }^{\text {a,b,* }}$, James Campbell ${ }^{c}$, Christine Griffin ${ }^{d}$, Harry Kaya ${ }^{\text {a,b }}$, Arne Peters ${ }^{\text {e }}$ \\ ${ }^{a}$ Department of Nematology, University of California, Davis, Davis, CA 95616, USA \\ ${ }^{\mathrm{b}}$ Department of Entomology, University of California, Davis, Davis, CA 95616, USA \\ ${ }^{\mathrm{c}}$ USDA ARS GMPRC, 1515 College Ave, Manhattan, KS 66502, USA \\ ${ }^{\mathrm{d}}$ Department of Biology and Institute of Bioengineering and Agroecology, National University of Ireland, Maynooth, Co. Kildare, Ireland \\ ${ }^{\mathrm{e}}$ E-Nema GmbH, Klausdorfer Str. 28-36, D-24223 Raisdorf, Germany
}

Received 9 June 2005; accepted 16 November 2005

Available online 18 January 2006

\begin{abstract}
We discuss the behavior and ecology of entomopathogenic nematodes in relation to their successes and failures as biological control agents. Four categories of studies have been reviewed herein; infective juvenile foraging strategies, recognition and evaluation of the host by infective juveniles, the actual behaviors of infective juveniles that result in infection, and the protective role of the symbiotic bacteria during nematode reproduction in the cadaver. This constitutes a chronological order of events. Two challenges are suggested. First, the data on entomopathogenic nematode behavioral ecology, while very extensive for some species, are almost completely lacking for most described species. We need to approach future studies paying more attention to phylogenetic origins of the traits that we study. Second, there is little consensus on exactly what are the traits that are worth studying. By reviewing and synthesizing current work, we make some suggestions about where future research should be directed.
\end{abstract}

(C) 2005 Elsevier Inc. All rights reserved.

Keywords: Behavior; Ecology; Entomopathogenic nematode; Infection; Host; Parasite; Insect; Steinernema; Heterorhabditis

\section{Introduction}

The behavior and ecology of entomopathogenic nematodes (i.e., steinernematids and heterorhabditids) have been studied in the past in attempts to make them better biological control agents. Indeed, their utility as biological control agents has spurred most of the research that has been conducted. Much of this work has been focused on their behavioral interactions with hosts. Several reasons have been put forward to explain the need for further understanding of entomopathogenic nematode behavior and ecology. Many of the papers published in this area, and grant proposals as well, have begun with a sentence resembling the following: "Entomopathogenic nematodes have great potential as biological control agents, but because of significant gaps in our

\footnotetext{
* Corresponding author.

E-mail address: eelewis@ucdavis.edu (E.E. Lewis).
}

knowledge of their foraging behavior (or infection strategies, host associations, etc.), this potential has not been realized."

Only relatively recently have entomopathogenic nematodes been the subject of more basic studies, where entomopathogenic nematodes are viewed as model organisms with which to ask questions about parasite biology in general. Entomopathogenic nematodes are excellent models for this purpose since they share the trait of having an active third stage infective juvenile (IJ) as the infective stage with many other parasitic nematode species. They have distinct experimental advantages over many animal parasites; they are easy and cheap to culture, they live from several weeks up to months in the infective stage and there is a large group of species which facilitates comparative studies. However, entomopathogenic nematodes differ from other parasitic nematodes because of their mutualistic association with bacteria. In this review, we address the basic studies that attempt to examine the theoretical underpinnings of 
entomopathogenic nematode behavior, and the potential applications of these findings to biological control of insect pests.

We cannot know all biological aspects of all species of entomopathogenic nematode. Therefore, we must pick and choose our questions and experimental subjects well. Here, we ask which aspects of entomopathogenic nematode biology are most important to understand to improve their success as biological control agents. We divide this review into four sections that describe the behavioral and ecological aspects of the infection process for entomopathogenic nematodes in chronological order. The first section describes host-finding behaviors and strategies. The second section, and next step in infection, is a mechanistic look at how IJs recognize hosts and how they gain entrance into the host hemocoel. Third is a section on infection strategies and the interaction between nematodes inside and outside the host. Finally, we examine the defense of the host cadaver from opportunistic competitors, specifically ants.

\section{Foraging strategies}

How organisms forage for resources can be described using different conceptual models. These models were originally developed for foragers other than entomopathogenic nematode infective stages, but are broadly applicable to many taxa and life histories. Two broad categories of conceptual models are (1) those based on the behavioral responses to sequentially encountered stimuli that vary in the quality of information that they convey and (2) those based on how searchers move through their environment. Both types of models can be applied to infective stage juvenile host foraging behavior. In the first category of models, host search is divided into a hierarchical process of host habitat location, host location, host acceptance, and host suitability (Doutt, 1964; Laing, 1937; Salt, 1935). This conceptual model has been widely adopted and has proven useful for understanding parasitoid host search behavior (Godfray, 1994). This hierarchical set of behaviors is not necessarily rigid (Vinson, 1981), and more recent models have emphasized the dynamic ranking of stimuli based on how closely they are associated with the host, forager internal state, and the amount of directional information provided by the cue (Godfray, 1994; Lewis et al., 1990; Vet et al., 1990).

Using the second category of models, foraging strategies are divided into two broad categories; cruise (widely foraging) and ambush (sit-and-wait) (Echkhardt, 1979; Huey and Pianka, 1981; McLaughlin, 1989; Pianka, 1966; Schoener, 1971). Classification is based on differences in how foraging time is allocated to motionless scanning versus moving through the environment (Huey and Pianka, 1981; O'Brien et al., 1989). Cruise foragers allocate more of their foraging time to scanning for resource-associated cues when moving through the environment, or during short pauses. Ambush foragers scan during long pauses that are interrupted by repositioning bouts of relatively short dura- tion. These differences are significant because the duration of scanning pauses influences the types of resources that the organism is likely to encounter. Cruise foragers have a higher probability of finding sedentary and cryptic resources than ambushers, and ambush foragers are more effective than cruise foragers at finding resources with high mobility. Extreme ambush and cruise foraging represent endpoints on a continuum of foraging strategies, rather than a strict dichotomy (Regal, 1978; Taigen and Pough, 1983). However, in many cases, foraging strategies of a group of species have a bimodal distribution that justifies the utilization of an ambusher/cruiser dichotomy (McLaughlin, 1989). The adoption of a particular foraging mode influences a range of related characters; forming what has been termed as an adaptive syndrome (Root and Chaplin, 1976). Thus, species that are distantly related taxonomically may share similar adaptive syndromes due to similarity in foraging mode (Echkhardt, 1979). The ambush foraging strategy may be particularly relevant for parasite infective stages that often search for hosts that are larger and more mobile than themselves (Campbell and Gaugler, 1993).

The two classes of models, hierarchical cues and ambusher/cruiser, are interconnected. Foragers typically respond behaviorally to hierarchical stimuli from the environment in ways that improve the probability or rate of encounter with a resource. The method of scanning, the relative importance of different stimuli, and the nature of the response will be influenced by foraging strategy (O'Brien et al., 1989, 1990). In response to information indicating that a forager is in a good patch, cruise foragers typically switch to movements that generate localized search (e.g., reduce speed, increase turning rate, turn biases) to remain in a patch (Bell, 1991). In contrast, ambush foragers in response to information indicating a higher quality patch may exhibit localized search by increasing the time spent in a scanning location (i.e., increase giving-up time) or using localized search movements during repositioning bouts (i.e., area-concentrated search).

Research into behavioral mechanisms of foraging has been heavily biased toward the more active cruise foragers; for example, the use of chemotaxis and localized search patterns in patches to facilitate finding resources (e.g., Bell, 1985; Huettel, 1986; Ramaswamy, 1988; Vet and Dicke, 1992). However, stimuli from the environment have also been demonstrated to be important for ambush foragers. Cues are used for selecting ambush sites (Greco and Kevan, 1994, 1995), assessing patch quality (O'Brien et al., 1990; Sonerud, 1992), and triggering resource capture behaviors (Bye et al., 1992). In response to external stimuli, foragers may shift along the continuum between ambush and cruise foraging. This can be accomplished by adjusting the allocation of time to either pausing or moving (O'Brien et al., 1990). This ability has been demonstrated for a number of species of insects, fish, birds, and lizards (Akre and Johnson, 1979; Formanowicz and Bradley, 1987; Inoue and Matsura, 1983; O’Brien et al., 1990). 
A number of relatively simple decision rules or rules-ofthumb for leaving a patch have been proposed (Stephens and Krebs, 1986), with the performance of a particular action (e.g., leaving a patch) being influenced by the distribution of prey within and between patches (Green, 1984; Iwasa et al., 1981; McNair, 1982). Many ambush foragers appear to use relatively simple rules-of-thumb (e.g., Janetos, 1982; Janetos and Cole, 1981; Kareiva et al., 1989). Parasite infective stages may use a fixed time or giving-up time rule; they use information other than prey capture or oviposition in evaluating patch quality and adjusting residence times (e.g., always leave a patch after some fixed amount of time has elapsed; leaving is a random process with a fixed probability, although the probability may be adjusted to different environmental conditions). For example, levels of hostassociated volatile cues can influence the patch leaving of parasitoid wasps (e.g., Hemerik et al., 1993; Waage, 1979). Information gained within a patch can influence not only the tendency to leave the current patch, but also the tendency to leave subsequently encountered patches (Shettleworth, 1984).

\subsection{Infective juvenile foraging mechanisms}

Infective juvenile small size, lack of appendages, limited sensory modalities and capabilities, and the size/mobility discrepancy between parasite and host constrain the hostseeking ability of entomopathogenic nematodes. The small size of the nematode IJ means that the surface tension of water films has a more profound influence on their behavior than gravity (Crofton, 1954). Nematodes are limited primarily to chemosensation, thermosensation, and mechanosensation to obtain information about their environment with which to make foraging decisions. The impact of these factors on three behaviors - crawling, standing, and jumping - is important in determining where along the continuum between ambush and cruise foraging a nematode IJ stage lies.

Most nematode species crawl by sinusoidal movement on the substrate using the surface tension forces associated with the water film to propel them forward or backward (Croll, 1970). Crawling nematodes may scan for environmental cues while crawling on the substrate or during short pauses. Environmental cues such as chemical and temperature gradients have been demonstrated to influence nematode crawling behavior (Bargmann and Mori, 1997; Croll, 1970; Dusenberry, 1980; Huettel, 1986; Zuckerman and Jansson, 1984). Crawling locomotion and the use of various kineses and taxes to locate hosts is consistent with a cruisetype of foraging strategy.

The infective stages of some entomopathogenic nematode species exhibit two additional behaviors that facilitate ambush foraging: standing and jumping. Most nematode species can raise the anterior portion of their body off the substrate and wave it back and forth. However, some species can elevate more of their body off the substrate and balance on a bend in their tail (Campbell and Gaugler,
1993; Ishibashi and Kondo, 1990; Reed and Wallace, 1965). This behavior has been termed 'winken' (Völk, 1950), 'nictation' (Campbell and Gaugler, 1993; Ishibashi and Kondo, 1990), and most recently 'standing' (Campbell and Kaya, 1999a,b, 2000). Standing behavior is restricted to the freeliving infective or dauer stages of certain species (Campbell and Gaugler, 1993, 1997; Campbell and Kaya, 2002). Standing behavior may function as both an immobile scanning bout and a mechanism to attack passing hosts.

Standing behavior is commonly observed in Steinernema (Campbell and Kaya, 2002). Among species that exhibit standing behavior, variation occurs in the duration of standing bouts and nematode activity while standing and this may be correlated with variation in foraging strategy. Some species have a stable standing behavior in which the nematode becomes straight and immobile and can maintain this posture, with interspersed periods of waving, for extended periods of time (Campbell and Kaya, 2002). Within Steinernema, standing behavior occurs in at least eight species, with stable long-term standing occurring only in Steinernema carpocapsae, S. scapterisci Nguyen and Smart, and S. siamkayai Stock, Somsook, and Reid (Campbell and Kaya, 2002). Standing behavior facilitates attachment to mobile hosts by reducing the surface tension holding the nematode to the substrate (Campbell and Gaugler, 1993). By raising the anterior region out of the water film, standing nematodes may also be scanning the environment for host-associated cues, such as volatile chemicals (Campbell and Kaya, 2000).

Jumps occur when an IJ is standing; the nematode forms a loop with its body that when released propels the nematode many times its body length through the air (Campbell and Kaya, 1999a,b, 2000; Reed and Wallace, 1965). The forces generated by the jumping mechanism of $S$. carpocapsae (Weiser) propel individuals many times their body length (Campbell and Kaya, 1999a,b). The frequency of jumping, like standing behavior, varies among species of Steinernema, but has not been reported in Heterorhabditis (Campbell and Kaya, 2002). Jumping can function as a means of dispersal and also as an ambush attack mechanism (Campbell and Kaya, 1999a). Jumping occurs in at least 11 species, with high rates of jumping expressed in the three species listed above and S. ceratophorum Jian, Reid, and Hunt. Although no standing or jumping has been reported in Heterorhabditis, there is no a priori reason to suspect that it could not occur in untested species in this genus.

\subsection{Interaction between foraging strategy and host- associated cues}

Cruise foragers range through the environment and are attracted to, or arrested by, cues that may indicate the location of a potential host. These behavioral mechanisms are consistent with the responses of a diverse range of cruise type foragers (Bell, 1991). Cruise foraging entomopathogenic nematode IJs move using relatively linear movement 
patterns that are typical of ranging search in the absence of host-associated cues (Lewis et al., 1992). Ranging movement is thought to maximize the area searched. During ranging search, cruise foragers typically respond to volatile cues, or cues dissolved in the water film, emanating from the host or its immediate environment. This response can be considered part of the hierarchical process of host habitat location and host location within its habitat. For example, cues emanating from plant roots (a potential host habitat) can influence entomopathogenic nematode behavior (Bird and Bird, 1986; Choo et al., 1989; Lei et al., 1992; van Tol et al., 2001). Cues from plants damaged by insect feeding provide more specific information about the presence of potential hosts and these chemical cues have been shown to increase attraction and infection by Heterorhabditis megadis (Rasmann et al., 2005; van Tol et al., 2001). Caryophyllene, the cue produced by damaged corn roots, is the first plant-produced compound to be identified to cause active recruitment of natural enemies in the soil.

Entomopathogenic nematodes also respond to specific cues produced by the insect itself. Lewis et al. (1993) found that Steinernema glaseri (Steiner) responded positively to volatile cues from an insect host and that this response was eliminated if $\mathrm{CO}_{2}$ was removed. Grewal et al. (1994) found a similar level of response to volatile cues for other cruise foraging entomopathogenic nematode species in Steinernema and for two species of Heterorhabditis. Recently, this strong response to volatile cues was extended to many Steinernema spp. that are effective at finding sedentary hosts (Campbell et al., 2003). Cruise foragers also respond to host contact cues. Lewis et al. (1992) found that S. glaseri switched to localized search (e.g., speed decreased, distance traveled decreased, proportion of time spent moving decreased) after contact with then removal from host-associated cues (e.g., cuticle, feces). Localized search is thought to maximize the chance that a searcher will either remain in a potentially profitable patch or reestablish contact with a host that was lost.

Ambush foraging entomopathogenic nematodes also respond to volatile cues, but their behavioral responses can be different from those of cruise foragers and are context specific. On smooth substrates, ambush foragers like S. carpocapsae exhibit ranging search, but they are not attracted to host volatile cues like $\mathrm{CO}_{2}$ without prior contact with a host (Lewis et al., 1993, 1995a). This response does not appear to result from a constraint in their sensory systems, because artificial selection can produce populations of nematodes that are attracted to host insects (Gaugler et al., 1989). Ambush foragers also do not switch to area-concentrated search in response to contact with host cues such as cuticle and feces like $S$. glaseri (Lewis et al., 1992). Although initially it was assumed that ambush foragers were just not as responsive to chemical cues as cruise foragers (Lewis et al., 1992), it has since become apparent that they do respond to chemical cues but their response is fundamentally different from cruise foragers. $S$. carpocapsae IJs when crawling on the substrate were not attracted to host volatiles, but they did respond to volatile cues after contact with host cuticle (Lewis et al., 1995a). This was proposed to occur because after a standing nematode contacted a host, it would be triggered to seek routes of entry into the host. Lewis et al. (1995a) proposed that ambush foragers are presented with cues in a more sequential fashion than cruise foragers and therefore only responded to cues if they were presented in the appropriate sequence.

Ambush foraging IJs also respond to volatile cues prior to host contact, but their responses are expressed only when nematodes are standing. Ambush foraging IJs presented with host-associated cues when standing start to wave back and forth and/or jump toward the source of the cue (Campbell and Kaya, 1999a, 2000). This appears to result from two types of cues: volatile chemical cues and air movement (a mechanosensory cue). This behavioral response increases the host attack area surrounding the standing IJ and can increase the probability of attaching to a host. This result indicates that standing IJs are scanning the environment actively and that they respond to host cues in a way that can increase the probability of host encounter.

One of the above-mentioned rules-of-thumb for parasite infective stages may be that when exposed to host volatile cues ambush foragers increase their giving-up time during standing. It is likely that potential hosts have patchy distributions in time and space at the soil surface. Therefore, some locations where nematodes stand will have a higher probability of host encounter than other areas. When a forager arrives at a patch, it has to decide how long to remain in that patch. If no host arrives within a certain period of time, there are two possible explanations: it is a poor patch or it is a good patch but by chance no hosts have yet arrived. Infective juveniles unlike predators or female parasitoids, do not have information on patch quality obtained directly by sampling resources within the patch, but may use chemical cues to evaluate patch quality. For S. carpocapsae, when host-associated cues were present, IJs were less likely to terminate a standing bout than when no host cues were present (Campbell et al., unpublished data). However, not all nematode species that stand also respond to host cues when standing.

Intermediate forager responses to host-associated cues were more variable than for species at either end of the continuum. Many intermediate foragers are attracted to host volatiles and switch to localized search in response to contact with host cuticle (Campbell et al., 2003). However, most species also exhibit standing and jumping behaviors. One intermediate forager, $S$. riobrave Cabanillas, Poinar and Raulston was found to have short duration standing bouts and standing giving-up time was not influenced by the presence of host cues (Campbell et al., unpublished data). Intermediate foragers also tended not to be triggered to jump by the sudden introduction of host cues and not to jump toward the source of cues (Campbell and Kaya, 2000). Of the species tested, only those entomopathogenic nematode species that are extreme ambushers tended to exhibit stable standing or have chemical cues trigger 
changes in standing bout duration and control the timing and direction of their jumps. These differences in characters suggest that intermediate foragers use host cues in a manner consistent with cruise foragers, although perhaps not as effectively, but because they can stand or jump they can also attach to moving hosts.

\subsection{Evolution of foraging strategies}

When comparing traits among species it is important to take into account the evolutionary relationships among the species being compared (Harvey and Pagel, 1991). Two species may share a trait due to common descent or because both species evolved under similar selection pressures. The mapping of behavioral traits onto a phylogeny of Steinernema provides a means of developing hypotheses about the evolution of forging strategies and the adaptive function of different behaviors within this group. A hypothesis of the evolutionary history of Steinernema was developed based on molecular and morphological characters (Stock et al., 2001). To investigate the evolutionary history of foraging behavior within Steinernema, behavioral, ecological, and morphological characters were mapped onto this phylogeny. The most basal clade within Steinernema contained $S$. carpocapsae S. scapterisci, and S. siamkayai, which were all classified as ambush foragers based on their host-finding and standing behavior. In another clade, all species were classified as cruise foragers based on both host-finding and their lack of standing behavior. The remaining species were either cruise or intermediate foragers based on at least one of the two criteria. Mapping of the jumping rate character on the phylogeny suggests that evolution of an increase or loss of jumping has evolved multiple times. Other traits such as host associations and habitat type can also be mapped onto phylogenies, but unfortunately our understanding of these traits for most species is limited to the extent that such mapping cannot be considered at this time.

Size is probably correlated with foraging strategy because IJs are non-feeding and have a fixed amount of stored nutrients, and cruise foragers may be larger [i.e., store more lipids (Selvan et al., 1993a)] than ambush foragers because active search is more energetically expensive. There is considerable variation in size among species of Steinernema (Stock et al., 2001). Campbell and Kaya (2002) noted that cruise foragers tended to have longer IJs than ambush foragers. The three species of the ambusher clade were all in the smallest size category and the species in the cruiser clade tended to be in the largest size categories. Intermediate foragers tended to be intermediate in size, but IJ size appears to be a highly plastic trait.

Based on the mapped traits, the ancestral species of Steinernema appears to be an intermediate forager. Given current taxon sampling, ambush foraging appears to have evolved once, whereas cruise foraging has evolved multiple times. Unfortunately, the replication needed to address questions about the assembly of traits associated with a given foraging strategy is not currently available. However, we can hypothesize that the ancestral Steinernema had the following traits; little or no standing behavior, low frequency of jumping, medium size, low level of attraction to host volatiles, and no change to localized search after host contact. As more species are described and characterized as to their host-finding behaviors, the evolution of foraging strategy in Steinernema may be more fully addressed.

\section{Recognizing and entering a host}

Once a nematode has reached the vicinity of an insect host, it must change its behavior to gain entrance into the hemocoel of that host. These behaviors could be energetically expensive and penetration into an unsuitable host could potentially be fatal to a nematode, due to either defense against infection (a lethal composition of gut fluids or a strong immune response against the nematode) or some other condition that would kill the infecting nematode. Ultimately, nematodes choosing an unsuitable host will not produce offspring and those choosing the suitable ones will. A certain capability of recognizing a suitable host before trying to enter can therefore be expected in entomopathogenic nematode populations. In contrast to "host finding," the term "host recognition" describes the reaction towards host stimuli which ultimately result in penetration into the host hemocoel.

How do entomopathogenic nematodes recognize hosts? It is most likely that nematodes react to chemical stimuli or that they sense the physical structure of the insect's integument. The stimuli might be associated with the host directly or with their by-products, like feces or volatile by-products of the insect's metabolism. Whether signals from the plants on which insect hosts feed are involved in host recognition has not been investigated. Host finding of weevil larvae by Heterorhabditis megidis Poinar, Jackson, and Klein, however, is mediated by signals from injured plant roots (van Tol et al., 2001).

To detect these stimuli, a part of the cascade of events involved in the penetration process must be assessed. Intuitively, the penetration rate, which is generally determined by counting the number of nematodes that enter an insect host, could serve as an indicator of how "stimulated" a population of entomopathogenic nematodes was by a particular host. However, there are too many other factors affecting penetration, like the physiological status of the insect, the impact of wounds to the insect's cuticle which might stimulate penetration of further nematodes, or the establishment of the symbiotic bacteria in the host which might trigger secondary invasion (Hay and Fenlon, 1995) or deter nematodes from entering (Glazer, 1997). A reliable screening for penetration stimuli must rely on specific events in the penetration cascade, not just how many nematodes end up inside a host. Recording the electrical activity of neurons is widely used to screen for stimuli in insects. Jones et al. (1991) were the first to use this method with plant parasitic nematodes and it may be worth trying with entomopathogenic nematodes. Another possibility is 
testing differential activity in RNA transcription. For example, Dolan et al. (2002) have used nucleic acid binding SYTO dyes to detect early events in dauer juvenile recovery of Heterorhabditis bacteriophora Poinar. To our knowledge, this method has not yet been used to visualize events in host recognition. By analyzing the regions where transcriptional activity is evoked by host stimuli, the physiological changes during host recognition can be elucidated. For instance, if enzymes are involved in the penetration process, transcriptional activity in the salivary glands of the dauer juveniles would be expected. Third, and most practically, excitement is visible by a change in locomotion behavior. The dog hookworm, Ancylostoma caninum (Ercolani) Hall, for example, starts penetrating into the agar surface in response to heat, dog serum, and hydrophilic skin washings of dogs (Granzer and Haas, 1991). Typical changes in locomotion behavior in response to surface washings of Tipula oleracea L. were observed for Steinernema feltiae (Filipjev) (Huneke et al., 1994). Steinernema carpocapsae, S. scapterisci, $S$. glaseri, and H. bacteriophora responded with behavioral changes to host feces (Grewal et al., 1993a,b). Head thrusting was presumed to be a penetration behavior that could be related to successful parasitism.

Entomopathogenic nematodes can penetrate to the hemocoel of a host through the cuticle, through the wall of the gut via the anus/mouth or through the tracheal cuticle via the spiracles. Thus, putative penetration stimuli may be located at these locations. Since penetration into non-suitable hosts is a dead end for that specific nematode genotype, it can be expected that nematodes recognize suitable hosts and that the response to host-associated stimuli and the ultimate success in establishing and propagating in a host is correlated. This was partially found for S. glaseri, $S$. carpocapsae, S. scapterisci, and H. bacteriophora with the hosts Spodoptera exigua (Hübner), Popillia japonica Newman, Blatella germanica (L.), and Achaeta domestica (L.) (Grewal et al., 1993a). The reaction of $S$. carpocapsae to contact with the integument of nine different insect species was studied by Lewis et al. (1996). Excitement was indicated by significantly faster movement towards volatile host cues after contact with the cuticle of a putative host. The nematodes responded differently to different host species and even to different stages of the same host species [larvae versus pupae of Agrotis ipsilon (Hufnagel)]. The levels of response were positively correlated with the susceptibility of the insect hosts tested and with reproductive success of the nematodes within the host. A notable exception to this rule was larvae of $P$. japonica which were not susceptible although $S$. carpocapsae responded positively to cuticle contact with this insect. It is likely that mechanical barriers (sieve plates that are located on the entrance to the spiracles in this species) exclude $S$. carpocapsae from the hemocoel. Hence, for $P$. japonica, host specificity acts at the time of penetration rather than recognition. The ambusher $S$. carpocapsae resides at the soil surface and would therefore rarely encounter root-feeding scarab grubs. Due to this spatial separation, avoiding the attempted penetration into
$P$. japonica was probably not under strong selection pressure in $S$. carpocapsae.

The nature of the materials in the insect's hemocoel that stimulate penetration remains unclear. Comparing three lepidopteran hosts, Khlibsuwan et al. (1992) reported a positive correlation between larval susceptibility and the attractiveness of their cell-free hemolymph to $S$. carpocapsae. Aqueous surface washings from $T$. oleracea triggered penetration behavior in S. feltiae. Possibly, hydrophilic components of the hemolymph which may be small enough to diffuse through the insect's integument trigger penetration behavior. Those substances should also be present in the tracheae and the intestine. Higher concentrations can be expected to diffuse at the intersegmental membranes which are known to be preferred penetration sites (Bedding and Molyneux, 1982; Blossey and Ehlers, 1991). For A. caninum, the component of dog serum that stimulated penetration behavior proved to be a small protein $(5-30 \mathrm{kDa})$. The component in the lepidopteran hemolymph attracting S. carpocapsae was less than $14 \mathrm{kDa}$ (Khlibsuwan et al., 1992).

The penetration rate through the integument or the intestine walls can be measured directly. Cui et al. (1993) established penetration sites in the alimentary tract of $P$. japonica by dissection. The intestine was filled with nematodes and closed, and the emergence from the intestine was then recorded. Sulistyanto (1997) constructed a chamber where pieces of insect cuticle could be fixed to separate two compartments. The experiments were done with $S$. feltiae and $H$. bacteriophora. Infective juvenile had to move through the integument to enter the water filled compartment where a putative penetration stimulant was added. Only if insect cues (i.e. aqueous surface washings, hemolymph or feces) were added to the attraction chamber did the nematodes penetrate. The integument itself did not trigger penetration. Interestingly, the cuticle of Phyllopertha horticola (Coleoptera: Scarabaeidae) and Galleria mellonella (L.) was penetrated by $S$. feltiae in the experiment, whereas no penetration of $G$. mellonella was recorded in vivo (Peters and Ehlers, 1994). Unfortunately, experiments with these penetration chambers were not continued. It would be a suitable design to characterise the nature and molecular weight of penetration stimuli. The weakness of this method, however, is that the integument is physiologically changed when removed from the insect. In addition to ruptures which may result from the dissection process, the chemical composition of an integument will change rapidly after it has been separated from the living insect.

Depending on the host and the nematode species, different routes of penetration are taken. One route of entry is through the mouth opening or the anus. The width of both openings (e.g., in wireworms) may exclude IJs (Eidt and Thurston, 1995), and insects' mandibles may crush the nematodes to death (Gaugler and Molloy, 1981). Using the anus as an entry site avoids the latter problem and represents the main route in house fly maggots and leafminers (Renn, 1998). Still, frequent defecation may expel nematodes entering the anus, and in grubs and sawfly larvae 
invasion is more successful via the mouth than via the anus (Cui et al., 1993; Georgis and Hague, 1981). When nematodes have reached the gastric caecae, malpighian tubules or the gap between the peritrophic membrane and midgut epithelium, expulsion with feces is avoided. Another general problem with parasite infection via the intestinal tract is the host's gut fluid, which may kill up to $40 \%$ of invading non-adapted nematodes and significantly reduce penetration via the intestine (Wang et al., 1995).

Alternatively, entomopathogenic nematodes may enter the tracheal system via the spiracles. In sawfly larvae, the spiracles are the most important route of entry by $S$. carpocapsae (Georgis and Hague, 1981). Other insect species, however, exclude invaders from the tracheal system by sieve plates. Entering the insect via the tracheal system is not possible in many scarab grubs (Forschler and Gardner, 1991), leatherjackets (Peters and Ehlers, 1994), and maggots (Renn, 1998).

Another site of penetration by entomopathogenic nematodes is the integument or the intersegmental membranes of an insect. Penetration through the integument was shown to be the main route of entry for S. feltiae into leatherjackets (Peters and Ehlers, 1994). Another port of entry to adult arthropods is the gonad openings. This is the main entry port for nematodes into ticks (Samish and Glazer, 1992).

After successfully entering the tracheal system or the intestine, the IJ still must pass through the tracheole or the gut wall, respectively. The fragile tracheole wall might be penetrated just by the mechanical pressure of the pointed nematode head. The gut wall, however, is in part protected by the peritrophic membrane, which can be a serious obstacle for nematodes (Forschler and Gardner, 1991). Steinernema glaseri IJs take 4-6h to penetrate from the midgut to the hemocoel of P. japonica (Cui et al., 1993); the nematodes preferably penetrate the midgut region and the gastric caecae. Infective juvenile $H$. bacteriophora were observed using their proximal tooth to rupture the insect body wall (Bedding and Molyneux, 1982) and it was long believed that only Heterorhabditis could penetrate tissues like the insect's integument, since IJs of Steinernema spp. lack the apical tooth. Reports of superior penetration of $S$. glaseri compared to H. bacteriophora through gut tissues of grubs (Wang and Gaugler, 1998) and of the penetration of $S$. feltiae through the integument of leatherjackets (Peters and Ehlers, 1994) challenged this perspective.

There is evidence that nematode secretions are involved in penetration, at least in Steinernema species. Protease inhibitors decreased penetration of $S$. glaseri through the gut wall of $P$. japonica (AbuHatab et al., 1995) and the midgut epithelium cells of $G$. mellonella showed a marked histolysis in response to secretions of axenic $S$. carpocapsae (Simoes, 1998). Penetration by $S$. feltiae through the cuticle of leatherjackets might be attributed to the absence of an epicuticular wax layer, which may block the activity of histolytic enzymes (Dowds and Peters, 2002).

When penetrating into the insect's hemocoel, the IJ encounters the non-self response by the immune system of the host. Nematodes can be trapped into cellular or noncellular capsules. The non-cellular capsules, consisting of melanin, are formed rapidly. In T. oleracea, IJs of $S$. feltiae have been found stuck in the cuticle and completely melanized (Gouge, 1994; Peters, 1994). Encapsulation of entomopathogenic nematodes has been reported in Orthoptera, Coleoptera, Diptera, and Lepidoptera (Dowds and Peters, 2002). Whether or not encapsulation occurs depends on the particular nematode species-insect species combination. In Acheta domesticus, the nematodes $S$. carpocapsae and $H$. bacteriophora are encapsulated, whereas $S$. scapterisci is not (Wang et al., 1994). Interestingly, S. scapterisci has been found naturally associated with the orthopteran Scapteriscus vicinus Scudder. Similarly, S. glaseri, which is often found associated with scarab larvae, is not encapsulated in $P$. japonica, in contrast to $S$. carpocapsae and $H$. bacteriophora, both of which elicit a strong encapsulation response. These findings suggest that nematodes are not encapsulated in hosts similar to those with which they are naturally associated.

Nematodes may resist encapsulation in insects by either avoidance of being recognized (evasion), by overwhelming the immune system by multiple infections and disrupting encapsulation (tolerance), or by actively suppressing the encapsulation response (suppression) (Dowds and Peters, 2002). The presence of the symbiotic bacteria increased encapsulation of $S$. feltiae in leatherjackets (Peters and Ehlers, 1997). At the same time, however, the bacteria suppress the immune response since they adhere to and kill the hemocytes (Dunphy and Webster, 1988). The period from nematode invasion to bacterial release is hence crucial for counteracting the encapsulation response.

The physiological and behavioral changes following host recognition are likely to increase the energy consumption of the nematodes. Increased energy consumption will subsequently shorten the life of the non-feeding IJ. Hence, unsuccessful penetration attempts must be costly. It is not exactly known, however, at what step in the cascade of events the IJ has irreversibly switched to a parasitic stage. Host penetration has been intensively studied in nematodes parasitic to vertebrates and plants. Elucidating this process for entomopathogenic nematodes will be a rewarding scientific challenge.

\section{Infecting a host}

For entomopathogenic nematodes a host insect represents not only a source of food but also a mating rendezvous, and so the decision to infect may be shaped by the need both to find suitable partners and resources and to avoid competition. The decision to infect (as well as the outcome of the attempt to infect subsequent to that decision) will obviously be influenced by host species and stage. Here, we are concerned with the influence of nematoderelated factors on the decision; both extrinsic (presence of other nematodes), and intrinsic (such as sex, age) to the deciding nematode. 


\subsection{Responses to hosts infected by conspecifics}

Entomopathogenic nematodes routinely infect hosts harboring conspecific nematodes. For a steinernematid to reproduce, there must be at least one member of the opposite sex present in the cadaver. Even for heterorhabditids and for Steinernema species in which most of the IJs develop into self-fertile adults (S. hermaphroditum Stock et al., 2004), the presence of conspecifics may be advantageous, facilitating outcrossing in subsequent generations. There may in addition be a requirement for "mass attack" or invasion by sufficient number of IJs to overcome the host's defenses (Peters and Ehlers, 1997). Above this minimum number required to provide mating partners and coattackers, every additional invading nematode is also a potential competitor. As crowding increases, the reproductive output per invading nematode is reduced (Boff et al., 2000; Koppenhofer and Kaya, 1995; Ryder and Griffin, 2002) and at very high densities no IJs at all are produced from the cadaver (Koppenhofer and Kaya, 1995; Selvan et al., 1993b). However, in the laboratory, both steinernematids and heterorhabditids continue to invade crowded hosts, reaching numbers well in excess of the host's carrying capacity. Some studies have reported no change in the proportion of nematodes invading over a range of exposure concentrations (Epsky and Capinera, 1993; Fan and Hominick, 1991a,b; Ryder and Griffin, 2002). Other studies, particularly those including a wider range of concentrations, have noted a decline in the proportion of nematodes invading with increasing concentration (Boff et al., 2000; Koppenhofer and Kaya, 1995; Selvan et al., 1993b) suggesting that under these conditions at least some nematodes detect and avoid overcrowded hosts. Such experiments, in which insects are simultaneously exposed to large numbers of IJs, probably do not reflect conditions in the field, where encounters would be spread out over longer periods, and so may fail to detect mechanisms for avoiding or deterring invasion into occupied hosts. Moreover it is possible that the nematodes' natural hosts emit signals in response to crowding that are not produced by the "unnatural" wax moth host used in lab studies.

Evidence for such a mechanism was reported by Glazer (1997), who demonstrated that invasion of Steinernema spp. (S. carpocapsae, S. riobrave, and S. feltiae) was significantly reduced 6-9h after injection of conspecifics into the hosts. Glazer produced evidence that initial infection by these nematodes induced the release of a chemical which deterred further invasion. There are only a few reports of inhibitory effects, such as that reported by Glazer (1997), though Wang and Ishibashi (1999) reported that cadavers harboring a single $S$. carpocapsae 48 h post-infection were less likely to be invaded by conspecifics than was an uninfected host. On the other hand, Campbell et al. (unpublished) found that hosts infected by $S$. feltiae $24 \mathrm{~h}$ previously were invaded in preference to uninfected hosts, and that natural infection up to $8 \mathrm{~h}$ previously had no effect on the infection decision of this species (in Glazer's experi- ments, S. feltiae were inhibited from entry 9 h post-injection with conspecifics). Further support for the phenomenon reported by Glazer would be welcome, particularly employing natural invasion rather than injection for the primary infection.

\subsection{Responses to hosts infected by heterospecifics}

Evidence both from the laboratory and from natural infections in the field suggests that entomopathogenic nematodes do not avoid insects harboring another species or even genus of entomopathogenic nematode. For example, S. carpocapsae and S. glaseri co-invade Galleria larvae in the laboratory (Koppenhofer et al., 1995; Wang and Ishibashi, 1999). Koppenhofer et al. (1995) found no effect on number of nematodes establishing in mixed versus single infections, whereas Wang and Ishibashi (1999) found that more $S$. carpocapsae invaded when mixed with $S$. glaseri than when alone. Such effects may be mediated directly by interactions between the IJs as well as indirectly through effects on the host. Failure to avoid a host infected by another species is not merely a laboratory artifact; for example, Bovien (1937) reported co-occurrence of S. feltiae and $S$. affine (Bovien) in bibionid larvae infected in the field. Species of Steinernema can develop together in the one insect host, though one species may suffer the effects of competition more than the other. It does not seem that there has been strong selection to avoid invading hosts harboring heterospecifics. Although both $S$. carpocapsae and $S$. glaseri were repelled by volatiles from insects infected with $S$. riobrave (Grewal et al., 1997), they both co-infected insects with $S$. riobrave (Koppenhofer and Kaya, 1996). However, the timing of invasion was not a factor in the latter study; both species may have co-invaded before the development of any species-specific signal, or $S$. riobrave may have invaded later.

Normally Heterorhabditis and Steinernema cannot coexist within a host, though clearly they can co-infect (Alatorrre-Rosas and Kaya, 1990); S. carpocapsae outcompeted $H$. bacteriophora unless the heterorhabditid was given a 6-h lead in time in the hemocoel (Alatorrre-Rosas and Kaya, 1991). Three species of Steinernema (though not S. carpocapsae) were attracted by volatiles from hosts infected with $H$. bacteriophora $4 \mathrm{~h}$ previously and, in the case of $S$. glaseri and $S$. arenarium (Artyuhovsky) (=anomali), the attraction was stronger than to other congenerically nematode-killed hosts (Grewal et al., 1997). The nature of the volatiles and their specificity were not identified. In addition, responses by Heterorhabditis to insects harboring heterospecifics have received less attention than those of steinernematids.

\subsection{Males (or females) as colonizers}

Grewal et al. (1993c) proposed that male steinernematids are the colonizing sex; that they disperse, locate and establish in distant hosts before females, and that parasitism by males renders the hosts more attractive to females. 
Evidence that males are more highly represented amongst the dispersing fraction than in the base population was presented for four of the five Steinernema species tested, including S. glaseri. Stuart et al. (1998) failed to support the male colonization hypothesis for S. glaseri, finding no temporal differences in colonization by males and females infecting Galleria in sand. The male colonization hypothesis remains controversial in relation to Steinernema. S. feltiae, the only species not showing male-biased dispersal in Grewal et al.'s (1993c) assays, may actually have a female-first strategy: Bohan and Hominick (1997a) reported a markedly female-biased sex ratio during the initial stages of the infection of $G$. mellonella, but with later invasion the sex ratio became balanced, as was the underlying population sex ratio. Further supporting evidence comes from the finding by Renn (1998) that male S. feltiae were found only in house fly larvae harboring 10 or more females. The temporal dynamics of this infection were not studied, and the flies were exposed to IJ entomopathogenic nematodes for a relatively short period $(4.5 \mathrm{~h})$. It might be expected that with longer exposure more males would have invaded. However, even with longer (3 day) exposure, males constituted less than $20 \%$ of the $S$. feltiae that invaded phorid fly larvae (Scheepmaker et al., 1998). These authors found that in cases of low establishment (1-5 nematodes/insect) only females were present in larvae most of the time, whereas at higher establishment rates, the phorid may not be large enough to support successful reproduction. The fact that in both Renn's and Scheepmaker et al.'s studies many insects contained only females indicates that the female bias does not arise from early-arriving males "defending" the insect and potential mates. Grewal et al. (1993c) suggested that the small size of $S$. feltiae's dipteran hosts accounted for it not having a male-colonizer strategy. However, as Scheepmaker et al. (1998) point out, a female-skewed sex ratio of invaders is a risky strategy in very small larvae.

Hay and Fenlon (1995) distinguished between a subpopulation of $S$. feltiae that would invade uninfected sciarid fly larvae and another subpopulation that would only invade infected hosts. The sex ratio of these two groups was not ascertained, but based on Renn's and Scheepmaker et al.'s findings for house fly and phorid larvae, together with Bohan and Hominick's results, it is likely that the primary invaders are largely females, while secondary invaders may be largely males.

\subsection{Phased infectivity}

Hominick and Reid (1990) proposed that on emergence from a host, some individuals are immediately infective, while others become dormant for a time. In this way, IJs produced from the same mother avoid competition with each other in crowded hosts near the source (the infected host from which they emerged). There are currently two concepts of "phased infectivity" in entomopathogenic nematodes. One model, proposed by Hominick and co-workers, is based on a switch between non-infectious and infectious nematodes, while the second, proposed by Griffin (1996), is based on graded levels of infectiousness. According to the more popular switch model, individuals in a population are either infectious or non-infectious, and the proportion of non-infectious individuals in the population may change over time (Bohan and Hominick, 1996, 1997b; Hominick and Reid, 1990). To demonstrate a non-infectious proportion, IJs must have unlimited opportunity to infect potential hosts (Campbell et al., 1999). An alternative explanation proposed to account for changes in infectivity over time is that individuals within a population vary in ability or motivation to infect, and that the level of ability or motivation may change in a graded manner over time (Griffin, 1996). Phased infectivity of this sort will not be detected when nematodes have unlimited access to hosts, as in such circumstances all individuals capable of infecting will eventually do so.

There are thus two questions: is there evidence for phased infectivity of any kind, and is there evidence of a temporarily non-infectious proportion of IJs? What is the evidence for phased infectivity? Bohan and Hominick (1997b) reported long-term fluctuations in infectivity of $S$. feltiae over 8 weeks at $15^{\circ} \mathrm{C}$, and interpreted this as a change in the size of the non-infectious proportion. Central to this interpretation is the assertion that the nematodes were given unlimited access to hosts. Campbell et al. (1999) tested infectivity with "sufficient suitable hosts" and found no evidence for the existence of a non-infectious proportion in three species of Steinernema $(S$. glaseri, S. feltiae, and S. carpocapsae). This calls into doubt the existence of phased infectivity sensu Bohan and Hominick in these species (or at least the strains tested). However, the temporal changes in infectivity reported by Bohan and Hominick (1996) may represent more subtle changes in infectivity - i.e., phased infectivity sensu Griffin (1996).

Griffin (1996) reported an increase in the infectivity of H. megidis IJs stored at $20^{\circ} \mathrm{C}$, reaching a peak after 3 weeks. In these assays, IJs were not given unlimited access to hosts and so the presence of a non-infectious proportion was not tested. Indeed, when given unlimited access to a host all infected. Griffin suggested that the increase in infectivity might represent an incremental improvement in responsiveness to host or an increase in general locomotor activity. However, subsequently it was shown that over the period during which there is an increase in infectivity of $H$. megidis, there is a decrease in locomotion and responsiveness to host volatiles, but an increase in "head-thrusting" in the absence of a host, which may reflect an increase in penetration motivation (Dempsey and Griffin, 2002). An increase in infectivity was also reported for $H$. bacteriophora stored at $22^{\circ} \mathrm{C}$ (Wojcik et al., 1986); this may represent (at least in part) a switch of some individuals from a non-infectious to infectious state (phased infectivity sensu Bohan and Hominick), as Campbell et al. (1999) found evidence for the existence of a non-infectious proportion in H. bacteriophora. 
There is evidence of cold-induced dormancy for entomopathogenic nematodes stored at $5-9^{\circ} \mathrm{C}$. Fan and Hominick (1991a,b) found that infectivity of S. feltiae and S. kraussei (Steiner) at optimal temperatures initially declined but then increased with time of cold-storage, resulting in a " $U$ shaped curve." Similar results were reported by Curran (1993) and for H. megidis by Griffin (1996). This may represent an overwintering strategy akin to the diapause of many types of parasitic nematodes (Wharton, 2004).

\subsection{Interactions between extrinsic and intrinsic conditions}

Many laboratory experiments demonstrate that the infection behavior of entomopathogenic nematodes may be quite complex and the decision whether to infect or not is influenced by several factors. Infection decisions are based on both host status (whether it is infected or not, the species and density of the resident nematodes, and how long they have been in occupation) and the status of the IJ (male or female, status of "infectivity," and age). It has been widely demonstrated that infectivity of IJs declines with age, especially as stored reserves are exhausted (e.g., Lewis et al., 1995b; Patel et al., 1997). By analogy with parasitoids, which tend to become less selective in placement of their eggs as they age (Godfray, 1994), it is likely that entomopathogenic nematodes also become less discriminating with age.

\section{Defense of the cadaver: the ant-deterrent factor}

Because nematode-killed hosts remain in or near the soil for at least 7 to 20 or more days before the infective stage emerges, the dead hosts may be utilized as a food resource by invertebrate saprophages before the IJs emerge. However, field tests demonstrated that workers of the Argentine ant, Linepithema humile (Mayr) did some foraging on nematode-killed larvae (Baur et al., 1998; Zhou et al., 2002), but in many instances, the nematode-killed insects were only partially consumed or not consumed at all. This response was not limited to the Argentine ant as other ant species in California, Hawaii, and Wisconsin showed similar responses (Table 1).

The nematode-killed insect and ant interaction showed that 4-day-old nematode-killed G. mellonella larvae placed on the soil surface in the field where Argentine ants were

Table 1

Ant species that have been affected by ant deterrent factor

\begin{tabular}{ll}
\hline Ants species & Reference \\
\hline Linepithema humile (Mayr) & Baur et al. (1998), Zhou et al. (2002) \\
Veromessor andrei (Mayr) & Baur et al. (1998) \\
Pheidole vistana Forel & Baur et al. (1998) \\
Formica pacifica Francoeur & Baur et al. (1998) \\
Monomorium ergatogyna Wheeler & Baur et al. (1998) \\
Pheidole megacephala (Fabricius) & Zhou et al. (2002) \\
Lasius alienus (Foerster) & Zhou et al. (2002) \\
Formica subsericea (Say) & Zhou et al. (2002) \\
\hline
\end{tabular}

foraging had very few to no scavenging ants on them, compared to freeze-killed control cadavers. Ants would initially touch the cadavers of G. mellonella infective with entomopathogenic nematodes with their antennae and in a few instances bite the cadavers with their mandibles, but further scavenging would immediately cease. If the integument of the cadaver was lacerated, the developing nematodes died because the cadaver would desiccate (Zhou et al., 2002). Thus, any encroachment of the integument, particularly in low moisture soils, would adversely affect nematode recycling.

The deterrence of ants from scavenging nematodekilled insects is due to a factor produced by the bacterial symbiont; insect larvae killed by direct injection of the bacterial symbiont are also protected from ant scavenging compared to frozen- or Bacillus thuringiensis Berlinerkilled controls (Baur et al., 1998). The data suggest that this deterrence is due to an ant-deterrent factor (ADF) produced by the bacterial symbionts, Xenorhabdus nematophila (Poinar and Thomas) and Photorhabdus spp. (Zhou et al., 2002).

ADF production was also noted with bacteria produced in vitro. Bacteria grown in laboratory culture and assayed in an ant-choice-test showed that the bacterial culture mixed with sucrose (the bait) had deterrent activity against ants (Zhou et al., 2002). Using this assay, ADF was characterized demonstrating that the compound(s) was heat stabile, sensitive to acid treatment, and less than $10 \mathrm{kDa}$ and may be a small, non-proteinaceous compound (Table 2) (Zhou et al., 2002).

Table 2

Characteristics of the ant deterrent factor

\begin{tabular}{|c|c|c|}
\hline \multirow{4}{*}{$\begin{array}{l}\text { Chemical and } \\
\text { physical } \\
\text { properties }\end{array}$} & $\begin{array}{l}\text { Molecular } \\
\text { weight }^{\text {a }}\end{array}$ & $\begin{array}{l}\text { Repellence conferred by }<10 \mathrm{kDa} \\
\text { fraction }\end{array}$ \\
\hline & Heat tolerance & $\begin{array}{l}\text { Repellence persists after } \\
\text { autoclaving }\left(20 \text { min at } 121{ }^{\circ} \mathrm{C}\right)\end{array}$ \\
\hline & $\begin{array}{l}\text { Acid/base } \\
\text { treatment }\end{array}$ & $\begin{array}{l}\text { Repellence decreased progressively } \\
\text { at lower } \mathrm{pH}(<6) \text {. Autoclaving } \\
\text { partially restored ADF activity at } \\
\text { low pH. }\end{array}$ \\
\hline & $\begin{array}{l}\text { Association with } \\
\text { cells }\end{array}$ & $\begin{array}{l}\text { Activity almost entirely in filter- } \\
\text { sterilized culture supernatant }\end{array}$ \\
\hline \multirow[t]{3}{*}{$\begin{array}{l}\text { Activity/ } \\
\text { spectrum }\end{array}$} & Ant species ${ }^{b}$ & $\begin{array}{l}3 \text { ant species are repelled with } \\
\text { differing sensitivities }\end{array}$ \\
\hline & Titration & $\begin{array}{l}5-20 \mathrm{X} \text { dilution eliminates } \\
\text { repellence }\end{array}$ \\
\hline & Strain survey & $\begin{array}{l}2 / 2 X . \text { nematophila strains produce } \\
\text { ADF } \\
2 / 5 \text { Photorhabdus } \text { strains produce } \\
\text { ADF } \\
\text { Escherichia coli does not produce } \\
\text { ADF }\end{array}$ \\
\hline Regulation & Secondary form ${ }^{\mathrm{c}}$ & Loss of repellence \\
\hline
\end{tabular}




\section{Conclusions}

In the past 10 years, great strides have been made in understanding entomopathogenic nematode behavioral ecology. In a review such as this, it is appropriate to ask "Where do we go from here?" Two sets of challenges confront us. First, of the 40+ described species in the Heterorhabditis and the Steinernema, almost all of the published information is focused on 5 or 6 of them. For example, we have referred to 10 Steinernema species and two Heterorhabditis species in a comprehensive review of the literature. Clearly, we need to consider the diversity that exists within these two genera more seriously. With new studies that consider phylogeny, such as Campbell et al. (2003), this situation is beginning to be addressed. By mapping characters, such as foraging strategy, onto a phylogeny we can begin to make predications about how new or unstudied species might behave. For example, if a new species is described and is closely related to $S$. carpocapsae, then we would predict that the IJ stages would forage by ambushing, spend significant time nictating, be able to jump, etc. Of course, to be able to make these predictions, we must first have the species described, which is a challenge beyond the scope of this review.

The second challenge we face is to determine which behaviors might be the most "important" to document. Given that it will not be possible to study all aspects of behavioral ecology for all species and strains, some list of priority behaviors and ecological attributes might be appropriate. Surely, at least one aspect of each of the main sections of this review should be given priority. A list of suggested behaviors might be useful to those who focus on surveying new areas for entomopathogenic nematode populations. Determining which behaviors would be best to study would depend on both the aspect of entomopathogenic nematode biology in question and the repeatability of the assay among all the various laboratories that would conduct it. This determination would also depend upon whether the focus of study is developing biological control agents or understanding behavioral ecology of entomopathogenic nematodes; what is important in each of these contexts could be quite different. Perhaps the biggest challenge will be to come to a consensus as a research community on what is important to know about entomopathogenic nematodes.

\section{References}

AbuHatab, M., Selvan, S., Gaugler, R., 1995. Role of proteases in penetration of insect gut by the entomopathogenic nematode Steinernema glaseri (Nematoda: Steinernematidae). J. Invertebr. Pathol. 66, 125-130.

Akre, B.G., Johnson, D.M., 1979. Switching and sigmoid functional response curves by damselfly naiads with alternate prey available. J. Anim. Ecol. 48, 703-720.

Alatorrre-Rosas, R., Kaya, H.K., 1990. Interspecific competition between entomopathogenic nematodes in the genera Heterorhabditis and Steinernema for an insect host in sand. J. Invertebr. Pathol. 55, 179-188.

Alatorrre-Rosas, R., Kaya, H.K., 1991. Interaction between two entomopathogenic nematode species in the same host. J. Invertebr. Pathol. 57, $1-6$.
Bargmann, C.I., Mori, I., 1997. Chemotaxis and thermotaxis. In: Riddle, D.L., Blumenthal, T., Meyer, B.J., Priess, J.R. (Eds.), C. elegans II.. Cold Spring Harbor Laboratory Press, Cold Spring Harbor, pp. 717-739.

Baur, M.E., Kaya, H.K., Strong, D.R., 1998. Foraging ants as scavengers on entomopathogenic nematode-killed insects. Biol. Contr. 12, 231236.

Bedding, R.A., Molyneux, A.S., 1982. Penetration of insect cuticle by infective juveniles of Heterorhabditis spp. (Heterorhabditidae: Nematoda). Nematologica 28, 354-359.

Bell, W.J., 1985. Sources of information controlling motor patterns in arthropod local search orientation. J. Ins. Physiol. 31, 837-847.

Bell, W.J., 1991. Searching Behavior: The Behavioral Ecology of Finding Resources. Chapman and Hall, London. p. 359.

Bird, A.F., Bird, J., 1986. Observations on the use of insect parasitic nematodes as a means of biological control of root-knot nematodes. J. Parasitol., 511-516.

Blossey, B., Ehlers, R.-U., 1991. Entomopathogenic nematodes (Heterorhabditis spp. and Steinernema anomali) as potential antagonists of the biological weed control agent Hylobius transversovittatus (Coleoptera: Curculionidae). J. Invertebr. Pathol. 58, 453-454.

Boff, M.I., Wiegers, C., Gerritsen, G.L.M., Smits, P.H., 2000. Development of the entomopathogenic nematode Heterorhabditis megidis strain NLH-E 87.3 in Galleria mellonella. Nematology 2, 303-308.

Bohan, D.A., Hominick, W.M., 1996. Investigations on the presence of an infectious proportion amongst populations of Steinernema feltiae (Site 76 strain) infective stages. Parasitology. 112, 113-118.

Bohan, D.A., Hominick, W.M., 1997a. Long term dynamics of infectiousness within the infective stage pool of the entomopathogenic nematode Steinernema feltiae (Site 76 strain) Filipjev. Parasitology 114, 301-308.

Bohan, D.A., Hominick, W.M., 1997b. Sex and the dynamics of infection in the entomopathogenic nematode Steinernema feltiae. J. Helminth. 71, 197-201.

Bovien, P., 1937. Some types of association between nematodes and insects. Videnskabelige Meddelelser fra Dansk naturhistorisk Forening $101,1-144$.

Bye, F.N., Jacobson, F.V., Sonerud, G.A., 1992. Auditory prey location in a pause-travel predator: search time and attack range of Tengmalm's owls (Aegolius funereus). Behav. Ecol. 3, 266-276.

Campbell, J.F., Gaugler, R., 1993. Nictation behavior and its ecological implications in the host search strategies of entomopathogenic nematodes (Heterorhabditidae and Steinernematidae). Behaviour 126, $155-170$.

Campbell, J.F., Gaugler, R., 1997. Inter-specific variation in entomopathogenic nematode foraging strategy: dichotomy or variation along a continuum? Fund. Appl. Nematol. 20, 393-398.

Campbell, J.F., Kaya, H.K., 1999a. How and why a parasitic nematode jumps. Nature 397, 485-486.

Campbell, J.F., Kaya, H.K., 1999b. Mechanism, kinematic performance, and fitness consequences of entomopathogenic nematode (Steinernema spp.) jumping behavior. Can. J. Zool. 77, 1947-1955.

Campbell, J.F., Kaya, H.K., 2000. Influence of insect associated cues on the jumping behavior of entomopathogenic nematodes (Steinernema spp.). Behaviour 137, 591-609.

Campbell, J.F., Kaya, H.K., 2002. Variation in entomopathogenic nematode (Steinernematidae and Heterorhabditidae) infective stage jumping behavior. Nematology 4, 471-482.

Campbell, J.F., Koppenhofer, A.M., Kaya, H.K., Chinnasri, B., 1999. Are there temporarily non-infectious dauer stages in entomopathogenic nematode populations: a test of the phased infectivity hypothesis. Parasitology 118, 499-508.

Campbell, J.F., Lewis, E.E., Stock, S.P., Nadler, S., Kaya, H.K., 2003. Evolution of host search strategies in entomopathogenic nematodes. J. Nematol. 35, 142-145.

Choo, H.Y., Kaya, H.K., Burlando, T.M., Gaugler, R., 1989. Entomopathogneic nematodes: host-finding ability in the presence of plant roots. Environ. Entomol. 18, 1136-1140.

Crofton, H.D., 1954. The vertical migration of infective larvae of strongyloid nematodes. J. Helminthol. 28, 35-52. 
Croll, N.A., 1970. The Behaviour of Nematodes: Their Activity, Senses, and Responses. Edward Arnold Ltd., London. p. 117.

Cui, L., Gaugler, R., Wang, Y., 1993. Penetration of steinernematid nematodes (Nematoda: Steinernematidae) into Japanese beetle larvae, Popillia japonica (Coleoptera: Scarabaeidae). J. Invertebr. Pathol. 62, 73-78.

Curran, J., 1993. Post-application biology of entomopathogenic nematodes in soil. In: Bedding, R., Akhurst, A., Kaya, H. (Eds.), Nematodes and the Biological Control of Insect Pests. CSIRO, Melbourne, Australia, pp. 67-77.

Dempsey, C.M., Griffin, C.T., 2002. Phased activity in Heterorhabditis megidis. Parasitology 124, 605-613.

Dolan, K.M., Jones, J.T., Burnell, A.M., 2002. Detection of changes occurring during recovery from the dauer stage in Heterorhabditis bacteriophora. Parasitology 125, 71-81.

Doutt, R.L., 1964. Biological characteristics of entomophagous adults. In: DeBach, P. (Ed.), Biological Control of Insect Pests and Weeds. Reinhold, New York, pp. 145-167.

Dowds, B.C.A., Peters, A., 2002. Virulence mechanisms. In: Gaugler, R. (Ed.), Entomopathogenic Nematology. CABI Publishing, Oxon, UK, pp. 79-98.

Dunphy, G.B., Webster, J.M., 1988. Virulence mechanisms of Heterorhabditis heliothidis and its bacterial associate, Xenorhabdus luminescens, in non-immune larvae of the greater wax moth, Galleria mellonella. Int. J. Parasitol. 18, 729-737.

Dusenberry, D.B., 1980. Behavior of free-living nematodes. In: Zuckerman, B.M. (Ed.), Nematodes as Biological Models, Volume 1. Academic Press, New York, pp. 127-196.

Echkhardt, R.C., 1979. The adaptive syndromes of two guilds of insectivorous birds in the Colorado Rocky Mountains. Ecol. Monogr. 49, 129149

Eidt, D.C., Thurston, G.S., 1995. Physical deterrents to infection by entomopathogenic nematodes in wireworm (Coleoptera: Elateridae) and other soil pests. Can. Entomol. 127, 423-429.

Epsky, N.D., Capinera, J.L., 1993. Quantification of invasion of two strains of Steinernema carpocapsae (Weiser) into three lepidopteran larvae. J. Nematol. 25, 173-180.

Fan, X., Hominick, W.M., 1991a. Efficiency of the Galleria (wax moth) baiting technique for recovering infective stages of entomopathogenic rhabditids (Steinernematidae and Heterorhabditidae) from sand and soil. Rev. Nematol. 14, 381-387.

Fan, X., Hominick, W.M., 1991b. Effects of low storage temperature on survival and infectivity of two Steinernema species (Nematoda: Steinernematidae). Rev. Nematol. 14, 407-412.

Formanowicz Jr., D.R., Bradley, P.J., 1987. Fluctuations in prey density: effects on the foraging tactics of scolopendrid centipedes. Anim. Behav. $35,453-461$.

Forschler, B.T., Gardner, W.A., 1991. Parasitism of Phyllophaga hirticula (Coleoptera: Scarabaeidae) by Heterorhabditis heliothidis and Steinernema carpocapsae. J. Invertebr. Pathol. 58, 396-407.

Gaugler, R., Campbell, J.F., McGuire, T., 1989. Selection for host-finding in Steinernema feltiae. J. Invertebr. Pathol. 54, 363-372.

Gaugler, R., Molloy, D., 1981. Instar susceptibility of Simulium vittatum (Diptera: Simuliidae) to the entomogenous nematode Neoaplectana carpocapsae. J. Nematol. 13, 1-5.

Georgis, R., Hague, N.G.M., 1981. A neoaplectanid nematode in the larch sawfly Cephalcia lariciphila (Hymenoptera: Pamphiliidae). Ann. Appl. Biol. 99, 171-177.

Glazer, I., 1997. Effects of infected insects on secondary invasion of steinernematid entomopathogenic nematodes. Parasitology 114, 597-604.

Godfray, H.C.J., 1994. Parasitoids: Behavioral and Evolutionary Ecology. Princeton University Press, Princeton, NJ. p. 473.

Gouge, D.H. 1994. Biological control of sciard flies (Diptera: Sciaridae) with entomopathogenic nematodes (Nematoda: Rhabditida), including reference to other Diptera. PhD Thesis, Department of Agriculture, University of Reading, UK, pp. 251.

Granzer, M., Haas, W., 1991. Host-finding and host recognition of infective Ancylostoma caninum larvae. Intern. J. Parasitol. 21, 429-440.
Greco, C.F., Kevan, P.G., 1994. Contrasting patch choosing by anthophilous ambush predators: vegetation and floral cues for decisions by a crab spider (Misumena vatia) and males and females of an ambush bug (Phymata americana). Can. J. Zool. 72, 1583-1588.

Greco, C.F., Kevan, P.G., 1995. Patch choice in the anthophilous ambush predator Phymata americana: improvement by switching hunting sites as part of the initial choice. Can. J. Zool. 73, 1912-1917.

Green, R.F., 1984. Stopping rules for optimal foragers. Am. Nat. 123, 30-40.

Grewal, P.S., Gaugler, R., Lewis, E.E., 1993b. Host recognition behavior by entomopathogenic nematodes during contact with insect gut contents. J. Parasitol. 79, 495-503.

Grewal, P.S., Gaugler, R., Selvan, S., 1993a. Host recognition by entomopathogenic nematodes: behavioral response to contact with host feces. J. Chem. Ecol. 19, 1219-1231.

Grewal, P.S., Lewis, E.E., Gaugler, R., 1997. Response of infective stage parasites (Nematoda: Steinernematidae) to volatile cues from infected hosts. J. Chem. Ecol. 23, 503-515.

Grewal, P.S., Lewis, E.E., Gaugler, R., Campbell, J.F., 1994. Host finding behaviour as a predictor of foraging strategy in entomopathogenic nematodes. Parasitology 108, 207-215.

Grewal, P.S., Selvan, S., Lewis, E.E., Gaugler, R., 1993c. Male insect-parasitic nematodes: a colonizing sex. Experientia 49, 605-608.

Griffin, C.T., 1996. Effects of prior storage conditions on the infectivity of Heterorhabditis sp. (Nematoda: Heterorhabditidae). Fund. Appl. Nematol. 19, 95-102.

Harvey, P.H., Pagel, M.D., 1991. The Comparative Method in Evolutionary Biology. Oxford University Press, Oxford, UK. p. 239.

Hay, D.B., Fenlon, J.S., 1995. A modified binomial model that describes the infection dynamics of the entomopathogenic nematode Steinernema feltiae (Steinernematidae: Nematoda). Parasitology. 111, 627-633.

Hemerik, L., Driessen, G., Haccou, P., 1993. Effects of intra-patch experiences on patch time, search time and searching efficiency of the parasitoid Leptopilina clavipes. J. Anim. Ecol. 62, 33-44.

Hominick, W.M., Reid, A.P., 1990. Perspectives on entomopathogenic nematology. In: Gaugler, R., Kaya, H. (Eds.), Entomopathogenic nematodes in biological control. CRC Press, Boca Raton, FL, pp. 327-345.

Huettel, R.N., 1986. Chemical communicators in nematodes. J. Nematol. $18,3-8$.

Huey, R.B., Pianka, E.R., 1981. Ecological consequences of foraging mode. Ecology 62, 991-999.

Huneke, J., Peters, A., Ehlers, R.-U., 1994. Movement patterns of dauer juveniles of Steinernema feltiae in response to host cues. Bull. IOBC SROP/WPRS 17, 112-115.

Inoue, T., Matsura, T., 1983. Foraging strategy of a mantid, Paratenodera angustipennis $\mathrm{S}$.: mechanisms of switching tactics between ambush and active search. Oecologia 56, 264-271.

Ishibashi, N., Kondo, E., 1990. Behavior of infective juveniles. In: Gaugler, R., Kaya, H.K. (Eds.), Entomopathogenic Nematodes in Biological Control. CRC Press, Boca Raton, FL, pp. 139-152.

Iwasa, Y., Higashi, M., Yamamura, N., 1981. Prey distribution as a factor determining the choice of optimal foraging strategy. Am. Nat. 117, 710-723.

Janetos, A.C., 1982. Foraging tactics of two guilds of web-spinning spiders. Behav. Ecol. Sociobiol. 10, 19-27.

Janetos, A.C., Cole, B.J., 1981. Imperfectly optimal animals. Behav. Ecol. Sociobiol. 9, 203-209.

Jones, J.T., Perry, R.N., Johnston, M.R.L., 1991. Electrophysiological recordings of electrical activity and responses to stimulants from Globodera rostochiensis and Syngamus trachea. Rev. Nematol. 14, 467-473.

Kareiva, P., Morse, D.H., Eccleston, J., 1989. Stochastic prey arrivals and crab spider giving-up times: simulations of spider performance using two simple "rules of thumb". Oecologia 78, 542-549.

Khlibsuwan, W., Ishibashi, N., Kondo, E., 1992. Response of Steinernema carpocapsae infective juveniles to the plasma of three insect species. J. Nematol. 24, 156-159. 
Koppenhofer, A.M., Kaya, H.K., 1995. Density-dependent effects on Steinernema glaseri (Nematoda: Steinernematidae) within an insect host. J. Parasitol. 81, 797-799.

Koppenhofer, A.M., Kaya, H.K., 1996. Coexistence of two steinernematid nematode species (Rhabditida: Steinernematidae) in the presence of two host species. Appl. Soil Ecol. 40, 221-230.

Koppenhofer, A.M., Kaya, H.K., Shanmugam, S., Wood, G.L., 1995. Interspecific competition between steinernematid nematodes within an insect host. J. Invertebr. Pathol. 66, 99-103.

Laing, J., 1937. Host-finding by insect parasites. I. Observations on the finding of hosts by Alysia manducator, Mormoniella vitripennis and Trichogramma evanescens. J. Anim. Ecol. 6, 298-317.

Lewis, E.E., Gaugler, R., Harrison, R., 1992. Entomopathogenic nematode host finding: response to host contact cues by cruise and ambush foragers. Parasitology. 105, 309-315.

Lewis, E.E., Gaugler, R., Harrison, R., 1993. Response of cruiser and ambusher entomopathogenic nematodes (Steinernematidae) to host volatile cues. Can. J. Zool. 71, 765-769.

Lewis, E.E., Grewal, P.S., Gaugler, R., 1995a. Hierarchical order of host cues in parasite foraging: a question of context. Parasitology 110, 207-213.

Lewis, E.E., Ricci, M., Gaugler, R., 1996. Host recognition behaviour predicts host suitability in the entomopathogenic nematode Steinernema carpocapsae. (Rhabditida: Steinernematidae). Parasitology 113, 573-579.

Lewis, E.E., Selvan, S., Campbell, J.F., Gaugler, R., 1995b. Changes in foraging behaviour during the infective juvenile stage of entomopathogenic nematodes. Parasitology 110, 583-590.

Lewis, W.J., Vet, L.E.M., Tumlinson, J.H., Van Lenternen, J.C., Papaj, D.R., 1990. Variations in parasitoid foraging behavior: essential element of a sound biological control theory. Environ. Entomol. 19, 1183-1193.

Lei, Z., Rutherford, T.A., Webster, J.M., 1992. Heterorhabditid behavior in the presence of the cabbage maggot, Delia radicum, and its host plants. J. Nematol. 24, 9-15.

McLaughlin, R.L., 1989. Search modes of birds and lizards: evidence for alternative movement patterns. Am. Nat. 133, 654-670.

McNair, J.N., 1982. Optimal giving-up times and the marginal value theorem. Am. Nat. 119, 511-529.

O'Brien, W.J., Browman, H.I., Evans, B.I., 1990. Search strategies of foraging animals. Am. Sci. 78, 152-160.

O’Brien, W.J., Evans, B.I., Browman, H.I., 1989. Flexible search tactics and efficient foraging in saltatory searching animals. Oecologia 80, $100-110$.

Patel, M.N., Stolinski, M., Wright, D.J., 1997. Neutral lipids and the assessment of infectivity in entomopathogenic nematodes: observations on four Steinernema species. Parasitology 114, 489-496.

Peters, A. 1994. Interaktionen zwischen den Pathogenitätsmechanismen entonopathogener Nematoden und den Abwehrmechanismen von Schnakenlarven (Tipula spp.) sowie Möglichkeiten zur Virulenzsteigerung der Nematoden durch Selektion. PhD Thesis, University Kiel, Germany.

Peters, A., Ehlers, R.-U., 1994. Susceptibility of leatherjackets (Tipula paludosa and Tipula oleracea; Tipulidae; Nematocera) to the entomopathogenic nematode Steinernema feltiae. J. Invertebr. Pathol. 63, 163-171.

Peters, A., Ehlers, R.-U., 1997. Encapsulation of the entomopathogenic nematode Steinernema feltiae in Tipula oleracea. J. Invertebr. Pathol. 69, 218-222.

Pianka, E.R., 1966. Convexity, desert lizards, and spatial heterogeneity. Ecology 47, 1055-1059.

Ramaswamy, S.B., 1988. Host finding by moths: sensory modalities and behaviors. J. Ins. Physiol. 34, 235-249.

Rasmann, S., Köllner, T.G., Degenhardt, J., Hiltpold, I., Toepfer, S., Kuhlmann, U., Gershenzon, J., Turlings, C.J., 2005. Recruitment of entomopathogenic nematodes by insect-damaged maize roots. Nature 434, 732-737.

Reed, E.E., Wallace, H.R., 1965. Leaping locomotion by an insect-parasitic nematode. Nature 206, 210-211.
Regal, P.J., 1978. Behavioral differences between reptiles and mammals: an analysis of activity and mental capabilities. In: Greenberg, N., MacLean, P.D. (Eds.), Behavior and Neurology of Lizards: An Interdisciplinary Colloquium Pub. 177-491. Department of Health, Education and, Welfare, Rockville, pp. 183-202.

Renn, N., 1998. Routes of penetration of the entomopathogenic nematode Steinernema feltiae attacking larval and adult houseflies (Musca domestica). J. Invertebr. Pathol. 72, 281-287.

Root, R.B., Chaplin, S.J., 1976. The life-styles of tropical milkweed bugs, Oncopeltus cingulifer and Oncopeltus unifasciatellus (Hemiptera: Lygaeidae) utilizing the same hosts. Ecology 57, 132-140.

Ryder, J.J., Griffin, C.T., 2002. Density dependent fecundity and infective juvenile production in the entomopathogenic nematode, Heterorhabditis megidis. Parasitology 125, 83-92.

Salt, G., 1935. Experimental studies in insect parasitism. III. Host selection. Proc. R. Soc. Biol. Sci. Series B. 114, 413-435.

Samish, M., Glazer, I., 1992. Infectivity of entomopathogenic nematodes (Steinernematidae and Heterorhabditidae) to female ticks of Boophilus annulatus (Arachnida: Ixodidae). J. Med. Entomol. 29, 614-618.

Scheepmaker, J., Geels, W.A., van Griensven, L.J.L.D., Smits, P.H., 1998. Susceptibility of larvae of the mushroom fly Megaselia halterata to the entomopathogenic nematode Steinernema feltiae in bioassays. BioControl 43, 201-214.

Schoener, T.W., 1971. Theory of feeding strategies. Ann. Rev. Ecol. System 2, 369-404.

Selvan, S., Campbell, J.F., Gaugler, R., 1993b. Density-dependent effects on entomopathogenic nematodes (Heterorhabditidae and Steinernematidae) within an insect host. J. Invertebr. Pathol. 62, 278-284.

Selvan, S., Gaugler, R., Lewis, E.E., 1993a. Biochemical energy reserves of entomopathogenic nematodes. J. Parasitol. 79, 167-172.

Shettleworth, S.J., 1984. Learning and behavioral ecology. In: Krebs, J.R., Davies, N.B. (Eds.), Behavioral Ecology: An Evolutionary Approach. Blackwell Scientific, Oxford, UK, pp. 170-194.

Simoes, N., 1998. Pathogenicity of the complex Steinernema carpocapsaeXenorhabdus nematophilus: molecular aspects related with the virulence. In: Simoes, N., Boemare, N., Ehlers, R.-U. (Eds.), Pathogenicity of Entomopathogenic Nematodes Versus Insect Defence Mechanisms: Impact on Selection of Virulent Strains. European Commission, Brussels, pp. 73-83.

Sonerud, G.A., 1992. Search tactics of a pause-travel predator: adaptive adjustments of perching times and move distances by hawk owls (Surnia ulula). Behav. Ecol. Sociobiol. 30, 207-217.

Stephens, D.W., Krebs, J.R., 1986. Foraging Theory. Princeton University Press, Princeton, NJ. 247 pp.

Stock, S.P., Campbell, J.F., Nadler, S.A., 2001. Phylogeny of Steinernema Travassos, 1927 (Cephalobina: Steinernematidae). J. Parasitol. 87, 877-889.

Stock, S.P., Griffin, C.T., Chaerani, R., 2004. Morphological and molecular characterisation of Steinernema hermaphroditum n. sp. (Nematoda: Steinernematidae), an entomopathogenic nematode from Indonesia, and its phylogenetic relationships with other members of the genus. Nematology 6, 401-412.

Stuart, R.J., Abu Hatab, M., Gaugler, R., 1998. Sex ratio and the infection process in entomopathogenic nematodes: are males the colonizing sex? J. Invertebr. Pathol. 72, 288-295.

Sulistyanto, D. 1997. Untersuchungen zum Wirkungspotential entomopathogener nematoden (Heterorhabditis spp.) zur biologischen Bek, mpfung von Engerlingen des Gartenlaubk, fers (Phyllopertha horticola). PhD Thesis, University Kiel, Germany.

Taigen, T.L., Pough, F.H., 1983. Prey preference, foraging behavior, and metabolic characteristics of frogs. Am. Nat. 122, 509-520.

van Tol, R.W.H.M., van der Sommen, A.T.C.M., Boff, I.C., van Bezooijen, J., Sabelis, M.W., Smits, P.H., 2001. Plants protect their roots by alerting the enemies of grubs. Ecol. Lett. 4, 292-294.

Vet, L.E.M., Dicke, M., 1992. Ecology of infochemical use by natural enemies in a tritrophic context. Annu. Rev. Entomol. 37, 141-172.

Vet, L.E.M., Lewis, W.J., Papaj, D.R., van Lenteren, J.C., 1990. A variable response model for parasitoid foraging behavior. J. Ins. Behav. 3, $471-491$ 
Vinson, S.B., 1981. Habitat location. In: Nordlund, D.A., Jones, R.L., Lewis, W.J. (Eds.), Semiochemicals, Their Role in Pest Control. John Wiley, New York, pp. 51-78.

Völk, J., 1950. Die Nematoden der Regenwürmer und aasbesuchenden Käfer. Zoologische Jahrbücher Abteilung Systematik 79, 1-70.

Waage, J.K., 1979. Foraging for patchily-distributed hosts by the parasitoid, Nemeritis canescens. J. Anim. Ecol. 48, 353-371.

Wang, X.D., Ishibashi, N., 1999. Infection of the entomopathogenic nematode, Steinernema carpocapsae, as affected by the presence of Steinernema glaseri. J. Nematol. 31, 207-211.

Wang, Y., Campbell, J.F., Gaugler, R., 1995. Infection of entomopathogenic nematodes Steinernema glaseri and Heterorhabditis bacteriophora against Popillia japonica (Coleoptera: Scarabaeidae) larvae. J. Invertebr. Pathol. 66, 178-184.

Wang, Y., Gaugler, R., 1998. Host and penetration site location by entomopathogenic nematodes against Japanese beetle larvae. J. Invertebr. Pathol. 72, 313-318.
Wang, Y., Gaugler, R., Cui, L., 1994. Variations in immune response of Popillia japonica and Acheta domesticus to Heterorhabditis bacteriophora and Steinernema species. J. Nematol. 26, 11-18.

Wharton, D.A., 2004. Survival strategies. In: Gaugler, R., Bilgrami, A.L. (Eds.), Nematode Behaviour. CABI Publishing, Wallingford, pp. 371-399.

Wojcik, W., Popiel, I., Grove, D. 1986. Is the pathogenicity of Heterorhabditis heliothidis dependent on prior history of temperature? In: 4th International Colloquium of Invertebrate Pathology, Veldhoven, The Netherlands, p. 319.

Zhou, X., Kaya, H.K., Heungens, K., Goodrich-Blair, H., 2002. Response of ants to a deterrent factor(s) produced by the symbiotic bacteria of entomopathogenic nematodes. Appl. Environ. Microbiol. 68, 6202-6209.

Zuckerman, B.M., Jansson, H.-B., 1984. Nematode chemotaxis and possible mechanisms of host/prey recognition. Ann. Rev. Phytopathol. 22, 95-113. 